\title{
Convivência com o semiárido: nas fronteiras entre o novo que se legitima e o antigo que teima em ficar?
}

Coexistence with the semiarid: between the new frontiers that legitimizes and the old insists on staying?

Mariana Moreira Neto - Doutora em Sociologia e professora da Universidade Federal de Campina Grande (UFCG/PB), Unidade Acadêmica de Ciências Sociais. Tem pesquisas com ênfase na sociologia rural em temas Relações de poder, Semiárido e Nordeste do Brasil. E-mail: moreiramariana@uol.com.br

Maria Thaize dos Ramos Lira - Historiadora, formada pelo Centro de Formação de Professores/Campus de Cajazeiras/UFCG. E-mail: thaize_ramosjp@hotmail.com

\section{Resumo}

Este artigo analisa como o discurso da convivência com o Semiárido é compreendido e ressignificado no contexto da vivência de entidades, organizações e agricultores do Alto Sertão Paraibano que trabalham com esta ideia, buscando apreender quais associações são estabelecidas entre convivência, desenvolvimento sustentável, sertão, autonomia e assujeitamento. Apreende-se que o discurso da convivência está entrelaçado a um diálogo conflituoso entre discursos, com outros olhares que muitas vezes acabam restringindo suas fronteiras, intervindo em suas ações e alterando o curso da sua institucionalização.

\section{Palavras-chave}

Semiárido. Convivência. Desenvolvimento sustentável. Resistências.

\begin{abstract}
This article analyzes how the discourse of coexistence with the semiarid is understood and reframed in the context of living entities, organizations and farmers of the High Hinterland Paraibano working with this idea, seeking to understand what associations are established between living, sustainable development, interior, autonomy and subjection. Is apprehended that the discourse of coexistence is interwoven to conflicting dialogue between discourses with other looks that often end up restricting its borders by engaging in their actions and altering the course of its institutionalization.
\end{abstract}

\section{Keywords}

Coexistence. Sustainable development. Resistance. 


\section{INTRODUÇÃO}

Ao se pensar o semiárido brasileiro, a imagem que vem à mente, a priori, é de uma localidade seca e inadequada ao convívio humano, ou seja, uma região periodicamente afetada por estiagens prolongadas que, manipuladas por grupos políticos e econômicos regionais, ditos oligárquicos, agrava a pobreza da população e corrobora o discurso de que a miséria é um castigo divino ou resultado da inviabilidade econômica e social. Um discurso que, valendo-se da literatura, reforça a imagem do sertanejo como condenado à retirância.

Ninguém pergunta ao retirante donde vem nem para onde vai. É um homem que foge do seu destino. Corre do fogo para a lama. [...] Baldarase lhe todo o heroísmo sertanejo. Ainda bem não se refazia de um cataclismo, sobrevinha-lhe outro. Horrendos desastres desorganizando a economia remanescente. $\mathrm{O}$ sertão vitimado: todo o seu esforço aniquilado pelo clima arrítmico, perturbador dos valores, regulador inconstante dos destinos da região (ALMEIDA, 1980, p. 29-31).

Estereótipos enaltecedores da miséria perpetuam por um longo período a visão de Nordeste, mas o que não se pode deixar de expor é que se trata de visões curtas e espaciais, que ofuscam a possibilidade de pensar cada indivíduo inserido no seu tempo. Assim, líderes políticos se apresentam como reforçadores desse discurso que associa o Nordeste apenas à seca e à fome e são, por muito tempo, gerenciadores de um meio representativo corrupto e falseado, fazendo uso da chamada indústria da seca para manter os seus meios de enriquecimento.

Os inúmeros discursos que se lançam sobre o Nordeste não surgem aleatoriamente, tampouco sem um foco. Eles objetivam, sobretudo, as barganhas políticas e financeiras apropriadas pelas chamadas elites regionais.

As políticas governamentais sempre foram acionadas a partir das necessidades extremas da população nos períodos de seca, mas sempre foram comandadas pelas elites regionais que controlavam a situação. Tanto a distribuição de cestas básicas, como a distribuição de água e a organização de frentes de trabalho foram controladas pelas elites e serviram para aumentar sua riqueza e seu domínio sobre a população (ÁGUA DE CHUVA, 2001, p. 14-15).

Deslocando essa concepção, uma nova leitura da região é empreendida, sobretudo por organizações não governamentais, que passam a apontar a ideia da convivência entre o homem e o meio ambiente como alternativa para se pensar a vida nesta região. Trata-se de uma concepção que compreende esse espaço como de interseção, encontro e convivência entre o homem e o seu meio. 
A nova releitura da região semiárida procura desmistificar a ideia de que o problema central desse espaço é a falta de água. Aponta também que o nordestino não deve abandonar o seu espaço, não sendo preciso deixar a sua localidade, mas adaptar-se a ela, quebrando a ideia de que no Nordeste não se vive. Este debate tem como principal suporte a ideia da convivência, que se apoia nos parâmetros do desenvolvimento sustentável como possibilidade concreta de construção de alternativas de vida e de promoção do protagonismo dos habitantes do Semiárido.

O discurso da convivência passa a ver o sertanejo não como um povo sofrido, ignorante, sem conhecimento algum; ou meros habitantes de um Brasil isolado e devastado pela fome, pelo descaso, pela miséria ou pelo atraso. As contribuições científicas que apresentam o Nordeste como uma localidade própria ao convívio são muitas, considerando ser esse,

[...] o Semiárido mais chuvoso do planeta: a pluviosidade é, em média, 750 $\mathrm{mm} /$ ano (variando, dentro da região, de $250 \mathrm{~mm} /$ ano a $800 \mathrm{~mm} / \mathrm{ano}$ ). É também o mais populoso, e em nenhum outro as condições de vida são tão precárias como aqui. O subsolo é formado em $70 \%$ por rochas cristalinas, rasas, o que dificulta a formação de mananciais perenes e a portabilidade da água, normalmente salinizada. Por isso, [...] a captação da água de chuva é uma das formas mais simples, viáveis e baratas para se viver bem na região (MALVEZZI, 2007, p. 10).

Essa nova compreensão de como devem ser construídas as relações entre o homem e a semiaridez passa necessariamente pelo viés da sustentabilidade, em suas múltiplas manifestações.

O que se busca é a abertura de uma nova cultura de relação com a chuva, uma nova cultura de conservação da água. Isso não é fácil, pois significa uma crítica a tudo que se tornou tradição na região e um despertar para caminhos novos de convivência com ela (POLETTO, 2001, p. 21).

Nesse sentido, a sustentabilidade está diretamente relacionada ao desenvolvimento econômico e material sem agredir o meio ambiente, considerado práticas sustentáveis de uso dos recursos naturais para que eles se mantenham no futuro. A questão que se apresenta como pertinente nesse debate é a de compreender como são estabelecidas as relações entre o homem e o meio, quais políticas e projetos são definidos na perspectiva da convivência, e como essa ideia se sustenta na proposta da sustentabilidade do desenvolvimento.

A temática que cerca o desafio da sustentabilidade ambiental requer em uma primeira análise a contemplação de mecanismos conceituais e estruturais que se evidenciam principalmente no que diz respeito à interação entre homem e natureza (GEWEHR, 2006, s.p.). 
A partir dessa compreensão, Chacon (1999) elenca alguns pontos que servem para destacar uma formulação do conceito de sustentabilidade, situados nas dimensões do social, do ambiental, do territorial, do econômico e do político. A observação desses critérios é apontada pela proposta da convivência como pré-requisito para que o desenvolvimento do Semiárido aconteça na interface entre as dimensões social, econômica, política, cultural e ambiental, ou seja, que a irregularidade das chuvas e a aridez do solo não sejam convertidas em argumentos políticos de legitimação e justificação da miséria regional. Portanto, viver no Semiárido se traduz em adequar-se às características da região por meio do uso racional dos seus recursos naturais, e favorecendo a autonomia e o protagonismo social. Portanto, a sustentabilidade se anuncia como a possibilidade concreta de produção de melhores perspectivas de vida e de valorização humana e social, rompendo com o ciclo vicioso do conformismo, que historicamente vem configurando as relações de poder nessa região.

Dessa forma, a proposta da convivência pode ser considerada como um novo discurso que se anuncia como possibilidade de produção da existência no Semiárido, quebrando paradigmas e instituindo novas concepções de mundo, reforçando o argumento de Foucault, para quem "o discurso não é simplesmente aquilo que traduz as lutas ou os sistemas de dominação, mas aquilo por que, pelo que se luta, o poder do qual nos queremos apoderar.” (FOUCAULT, 1999, p. 10).

\section{NUANCES E INTRIGAS DO VELHO QUE SAI E DO NOVO QUE CHEGA}

A compreensão das associações que são estabelecidas entre a ideia de convivência e de desenvolvimento sustentável, a partir da prática de entidades que trabalham com esta proposta no Alto Sertão Paraibano, permite apreender como esse discurso é significado e ressignificado no cotidiano dessas entidades, e quais elaborações e reelaborações ele opera na produção de relações de poder que perpassam e situam o dizer da convivência. Também se apresenta como imperativo a compreensão elaborada pelos agricultores acerca da convivência com o Semiárido, bem como as suas divergências e convergências para com as maneiras de apropriação do poder por parte das entidades.

De acordo com Foucault (1999), é pertinente ter a compreensão de como os discursos vinculados a uma prática que provém da formação de saberes se instituem como um espaço em que poder e saber se articulam para construir subjetivações socioculturais e criar identidades. Aprofundar esses discursos em 
seu poder de afirmação, de construção de domínios, de objetos de codificação e de correlações de forças como pontos de interseção entre saber e poder apresentouse como um pressuposto determinante na compreensão de como o discurso da convivência com o semiárido transita e oscila entre a legitimidade e a resistência.

A partir dessa compreensão, e seguindo a linha argumentativa construída por Foucault, percebe-se que a produção de um processo criativo das lutas de resistência constitui uma nova economia das relações de poder, pois "tudo isso está diretamente ligado a uma prática e às estratégias que são, por sua vez, moveis e se transformam" (FOUCALT apud BRANCO, 2001, p. 7). Foucault ainda concede lugar às variadas modalidades de lutas em jogo na atualidade. Elas se evidenciam no campo dos afrontamentos ao poder, nas pelejas e nas

[...] lutas contra a dominação (étnicas, sociais, religiosas), [n] as lutas contra as formas de exploração (que separam o indivíduo do que ele produz), e finalmente [n] as lutas que levantam a questão do estatuto do indivíduo (lutas contra o assujeitamento, contra as diversas formas de subjetividade e submissão)" (FOUCAULT apud BRANCO, 2001, p. 9).

Sendo assim, compreende-se que as lutas de resistência são lutas pela autonomia e emancipação. Neste sentido, apreende-se como o discurso da convivência com o semiárido se contrapõe a um discurso tradicional que desenha o sertão e, consequentemente, o sertanejo como um povo sofrido, ignorante, sem conhecimento algum ou mero habitante de um Brasil isolado e devastado pela fome, pelo descaso, pela miséria ou pelo atraso. As contribuições teóricas que constroem e subsidiam o discurso da convivência com o semiárido, bem como a prática das entidades que trabalham a ideia da convivência e as falas das lideranças e dos agricultores buscam referenciar o espaço do semiárido como um espaço de aprendizagem. Ou seja, é preciso aprender a conviver, adaptando-se ao meio e construindo relações de interação entre o homem e o meio ambiente.

É possível perceber como o discurso da convivência é apropriado e reelaborado a partir dos interesses e das intencionalidades históricas que marcam cada momento e cada experiência das entidades, no percurso de suas práticas cotidianas. As análises permitidas pelos discursos e falas das entidades, lideranças e agricultores possibilitam auferir que a convivência com o semiárido é uma questão de saber lidar com a estrutura que o clima disponibiliza, a partir da construção de cisternas de placa, mandalas, banco de sementes comunitário, barragem subterrânea, armazenagem da ração forrageira, criação de animais, além de respeitar e zelar pelo meio ambiente e evitar o uso de agrotóxicos. A configuração de um discurso político sobre a convivência pode ser evidenciado no exemplo da cisterna de placa, que emerge das falas de forma dominante, como 
um artefato que não traz apenas água, mas também a autonomia das famílias em relação aos grupos políticos que ao longo de décadas escravizaram a população com a utilização de carros-pipa e outras esmolas públicas.

\section{QUEM FALA EM NOME DA CONVIVÊNCIA DIZ O QUE?}

A compreensão da convivência como estratégia de construção da dignidade da vida no semiárido se expressa no desenvolvimento de saberes e experiências que possibilitam aos homens e mulheres que vivem neste espaço ressignificar os saberes e modos de vida, transformando concepções políticas e desmistificando crenças. A convivência é vista além de uma compreensão climática ou meteorológica, assumindo dimensões política, cultural e mesmo religiosa, quando passa a ser incorporada como motivação para a ação de entidades religiosas, como a Comissão Pastoral da Terra (CPT-Sertão).

Para a CPT-Sertão a convivência com o semiárido é uma questão de saber superar as adversidades do clima. É o armazenamento de água e de sementes, como também o manejo adequado da terra, possibilitando, assim, a pastagem para os animais. É uma garantia de sobrevivência dos seres humanos, dos animais e da produção, e por mais que seja uma região onde a chuva é irregular, as pessoas têm que se conscientizar de que é necessário de armazenar, pois, caso contrário, enfrentarão sérias dificuldades no período de estiagem.

A elaboração da convivência explicita como os discursos são articulados a partir das posições e dos lugares que os sujeitos ocupam, o que empresta legitimidade e reconhecimento às suas falas. A percepção de como é morar no sertão está imbricada na desconstrução da ideia de combate à seca, e a instituição de uma nova concepção que elege e aponta a positividade das inúmeras possibilidades de se viver no sertão, que são negligenciadas pelo discurso dominante assentado na compreensão da seca como determinação natural.

Nesse sentido, as elaborações discursivas produzidas pela CPT-Sertão, revelam como a idéia da convivência vem atrelada a uma mudança de concepção que se processa no curso de ações educativas e formativas que positivam o semiárido como possibilidade e desconsideram o sertão como espaço da fome, da miséria, do degredo. Tais elaborações discursivas permitem apreender como ocorre o deslocamento de sentidos e a legitimação de novos discursos. Percebese, pois, como o discurso da convivência com o semiárido começa a se instituir no imaginário sertanejo, suplantando a compreensão prevalecente até algumas décadas atrás, quando as pessoas pensavam que seria possível acabar com a seca, 
não dando importância ao fato de ela ser um fenômeno climático natural. A convivência com o semiárido o está imbricada por uma relação de aprendizagem, ou seja, aprender a respeitar o meio em que se vive, estabelecendo estratégias de sobrevivência.

O respeito ao meio em que se habita é o passo principal para a convivência, pois é a partir dele que se consegue estabelecer estratégias de sobrevivência. Nessa região de clima semiárido, a sustentabilidade torna-se uma prática essencial, desde o momento em que as pessoas aprendem a respeitar a natureza e interagem com o contexto social, político e cultural em seu entorno.

O discurso da convivência emerge ainda nas elaborações discursivas das entidades, como uma estratégia fundamental para a produção de novas concepções, novas formas de descrever um lugar e novos modos de situá-lo e contextualizá-lo historicamente. Isso fica evidente nas falas das lideranças da Central das Associações dos Assentamentos do Alto Sertão Paraibano (CAAASP). $\mathrm{Na}$ configuração elaborada e legitimada pelas entidades e por suas lideranças, A convivência com o semiárido se assenta na proposta da relação racional e respeitosa do homem com o meio e, a partir dos projetos e das atividades, valorizar a cultura e as experiências das gerações passadas, e pensar o futuro com autonomia e determinação.

Essa compreensão reforça o argumento de que é possível conviver no semiárido desde que se aprenda a lidar com as condições que ele disponibiliza. Para tanto, a educação, sobretudo aquela que se processa no âmbito das formações políticas e técnicas, tendo como referência o aspecto da contextualização, destaca-se como imperativa. Pois, para tornar possível a convivência é necessário demonstrar que "conviver com a seca não é fácil, mas é possível", tanto através de palestras ou cursos de capacitação, quanto de outras atividades e projetos que promovam a interação social, embasados na proposta da convivência com o semiárido.

O discurso da convivência também ganha legitimidade em outras instâncias através da atuação, por exemplo, de entidades sindicais, sobretudo de trabalhadores rurais, como parceiras na execução de programas e projetos que têm a proposta da convivência como pressuposto fundamental. Isso fica evidente nas falas de lideranças do Sindicato dos Trabalhadores Rurais de Aparecida, que constroem o discurso da convivência a partir do viés do protagonismo social e político dos habitantes dessa região, e de suas ações voltadas para o desenvolvimento sustentável e promoção da autonomia social, do desenvolvimento de tecnologias sociais adaptadas à realidade do Semiárido e da geração de renda. 
A construção de um discurso articulado e socialmente referenciado sobre a convivência é perceptível quando as lideranças sindicais afirmam que é necessário chegar a "uma compreensão de que ninguém pode acabar com a seca e que se vive em uma região de quadro seco". A proposta da convivência com o semiárido passa, portanto, pelo desenvolvimento de experiências que municiam a população para suportar a época de estiagem. Um discurso que expressa o entendimento de como as entidades e instituições que elaboram e produzem a proposta da convivência ganham um lastro de verdade e de concepção política de um espaço ao legitimar uma possibilidade de vida para o semiárido. Neste sentido, a proposta da convivência ressignifica antigas concepções, sobretudo a de que, em períodos de estiagens, eram naturais as práticas das esmolas públicas no intuito de combater a seca.

Desponta como fundamental, ainda, a questão de que é importante a discussão da convivência, porém ela tem de ser sustentável,

[...] tem que levar para a mesa do governo, é como uma obrigação, a concepção de entendimento do desenvolvimento da região. Até um dia desses só existia Estado de Campina Grande para lá, Sertão não existia. Hoje estamos todos discutindo desenvolvimento sustentável, agroecologia. Enfim, sementes da paixão, região, sementes que sejam produzidas pelos próprios trabalhadores, e não aquela semente introduzida pela EMBRAPA. O desenvolvimento sustentável deve estar aliado como o semiárido. A convivência é você aprender a lidar com as condições que a região lhe oferece. (INSERIR AUTOR, ANO, PÁGINA)

Essas práticas discursivas consideram e legitimam a compreensão de que não adianta querer acabar com a seca, pois ela é um fenômeno climático, e não cabe aos seres humanos alterar essa realidade. Percebe-se que a proposta da convivência vem se institucionalizando como um discurso que, cada vez mais, ganha projeção como uma forma de ver e dizer sobre esta região. Nesse sentido, observa-se que as entidades trazem, como conseqüência principal, o redimensionamento do lugar que os sujeitos sociais ocupam e as estratégias e táticas utilizadas na produção desse espaço.

Observa-se, ainda, que a interseção entre convivência e sustentabilidade vem marcando os empreendimentos desenvolvidos na região, e estabelecendo novos paradigmas na relação que os homens constroem entre si e com o meio ambiente. As práticas de armazenamento da água da chuva, de manejo sustentável da caatinga, de educação contextualizada, a preservação dos recursos hídricos se constitui, portanto, nas formas de promover uma articulação harmoniosa entre o homem e o meio ambiente. Desta forma, visando superar o sofrimento 
político e social provocado pelas estiagens, reelaborando relações de poder-saber que valorizem o protagonismo e a vivência no espaço semiárido, o discurso da convivência se insinua como uma possibilidade de criar condições de vida sobre este espaço com as adversidades climáticas e naturais que lhes são peculiares.

Os ditos e escritos que fornecem subsídios para a compreensão do que é o semiárido, a partir da visão das entidades e lideranças, embasam a percepção de que não é necessário abandonar o sertão e partir em busca de melhores condições de vida, pois a comunidade produz suas estratégias de convivência.

\section{ENTRE O QUE CHEGA COMO NOVIDADE E O MEDO DO ASSUJEITAMENTO}

As falas dos agricultores, por sua vez, revelam diversas formas de elaborar discursos e expressam concepções que são, por vezes, distintas e divergentes. Percebe-se que enquanto a versão dos líderes das entidades remete ao campo das possibilidades e da aceitação do discurso da convivência como legítimo, circulam outras versões que destoam e divergem dessa ideia.

Analisar os mecanismos de resistência configura-se como um tema relevante, quando se apreende como, em determinados momentos, os agricultores manifestam posições de descontentamento, de divergência, de não aceitação e de resistência às práticas e aos discursos veiculados por entidades e lideranças, que buscam, de forma determinante, diluir as individualidades em um contexto totalizante.

[...] a individualidade é completamente controlada pelo poder e que nós somos individualizados, no fundo, pelo próprio poder. Dizendo de outro modo, eu não creio que a individualização se oponha ao poder, mas, pelo contrário, eu diria que nossa individualidade, a identidade obrigatória de cada um é efeito e instrumento do poder, e o que este mais teme é: a força e a violência dos grupos (FOUCAULT, 1994, p. 663).

A partir da análise das falas dos agricultores que manifestam alguma resistência e/ou divergência ao discurso da convivência e da ação de lideranças das entidades que trabalham essa proposta na região, percebe-se que, embora destaquem a relevância de alguns projetos que vislumbram a possibilidade de uma melhor relação do homem com o meio ambiente, frente as suas peculiaridades de aridez, revelam a atuação das entidades e das pessoas que as representam, criando certa hierarquia e instituindo relações de poder que inibem ou impedem a participação de todos. Neste sentido, as falas dos agricultores permitem 
identificar um sentimento de desconfiança em relação às lideranças e ao discurso que elas elaboram e representam, sobretudo quando esses agentes passam a atuar nas comunidades, demonstrando, enfim, um clima de tensão ante a perda das individualidades e o risco do assujeitamento a um discurso e às práticas que lhes são correlatas.

As falas expressam como as resistências e discordâncias são evidenciadas. Uma posição que traduz um distanciamento e ruptura não revelados nas falas das lideranças, quando defendem que a convivência com o Semiárido é a garantia de sobrevivência dos seres humanos, dos animais e da produção, e que, por mais que seja uma região onde a chuva é irregular, as pessoas têm que se conscientizar de que é necessário armazenar água, pois, caso contrário, passarão por sérias dificuldades no período de estiagem. Nesse cenário, não se consideram as posições e os lugares dos homens no intricado mundo das relações de poder, que se manifestam nas suas variadas matizes, nem, portanto, as individualidades que permeiam os embates e as resistências.

Neste sentido, Branco (2001), ao analisar a questão, considera que, na visão foucaultiana,

[...] as lutas de resistência em torno do estatuto da individuação podem ser sintetizadas pela seguinte palavra de ordem: "sem dúvida, o objetivo principal, hoje, não é o de descobrirmos, mas o de nos recusarmos a ser o que somos". De tal modo que o problema não está tão somente no Estado e nas suas instituições, mas, sobretudo, na própria esfera subjetiva, onde eles têm uma influência produtiva de aniquilação do moto próprio da condição livre. A questão, assim, é produzir, criar, inventar novos modos de subjetividade, novos estilos de vida, novos vínculos e laços comunitários, para além das formas de vida empobrecidas e individualistas implantadas pelas modernas técnicas e relações de poder (BRANCO, 2001, p. 10).

Apesar de não participarem ativamente de todos os projetos desenvolvidos pelas entidades, os agricultores que não partilham do mesmo entendimento do discurso da convivência, reconhecem que muitas ações representam uma possibilidade de conviver melhor com o semiárido. Um caso especial é a construção de cisternas de placa, permitindo que as pessoas tenham acesso à água no período de estiagem, que atualmente tem uma aceitação majoritária na região, e que, independente de um envolvimento direto ou não com a proposta da convivência com o Semiárido, ressignificaram e ressignificam uma compreensão sobre o sertão e o Semiárido. No entanto, essa compreensão não se legitima como uma ideia.

Esses discursos nos permitem perceber até que ponto e em que medida o discurso da convivência é apropriado e reelaborado a partir dos interesses e 
das intencionalidades históricas que marcam cada momento e cada experiência dos agricultores, no percurso de suas práticas cotidianas. Há determinadas falas que não podem ser divorciadas do contexto histórico em que são elaboradas, ou seja, da realidade e da vivência nas comunidades ou nos assentamentos aos quais os agricultores estão vinculados. Neste sentido, compreender essas falas implica situá-las enquanto ditos sobre um espaço e uma contextualidade, e que, em vários momentos se afinam ou destoam da realidade em que vivem, produzindo múltiplas versões dos fatos e gerando outros olhares sobre as práticas trabalhadas pelas entidades.

\section{CONSIDERAÇÕES FINAIS}

À revelia das ressalvas e prevenções que se manifestam de forma recorrente nas elaborações discursivas, sobretudo de agricultores, já desponta como uma evidência real a constatação de que o discurso da convivência é elaborado e reelaborado por cada assentado, em consonância com suas práticas cotidianas e posições políticas, fato que favorece que determinadas vivências e experiências sejam aceitas e legitimadas, mesmo quando há posturas pessoais divergentes.

Outra expressão das divergências que marcam o discurso da convivência é revelada quando se analisa a forma como são compreendidos, interpretados e ressignificados os projetos e as ações. As classificações e divisões políticas e culturais que definem as posições e concepções dos sujeitos, como lideranças, técnicos e agricultores, revelam um processo de institucionalização que hierarquiza, e de certa forma determina as exclusões e privilégios, gerando situações em que pessoas são referenciadas como "donas" das entidades.

Neste sentido, em muitos aspectos dos discursos são perceptíveis as resistências e as dissonâncias que entremeiam e perpassam a proposta da convivência com o Semiárido, e a sua vivência e operacionalização através dos projetos e ações que são executados e realizados por diversas entidades no Alto Sertão Paraibano. A omissão e o desinteresse em participar das ações, a crítica a hierarquização das entidades, a maneira desigual com que os projetos são distribuídos nas comunidades, a forma como as lideranças concentram poder e, dessa forma, instituem e estabelecem relações assimétricas entre as comunidades produzem situações em que as entidades são procuradas somente em momentos pontuais, como a necessidade de um documento. É frequente a demonstração de descaso quanto à atuação das lideranças e a cobrança e crítica em relação à falta de diálogo, levando um assentado a afirmar que "já arrumei muita intriga por não aceitar as coisas do jeito deles". 
Uma avaliação das falas dos agricultores e das lideranças das entidades permite apreender que essa proposta vem, cada vez mais, ganhando legitimidade, como forma de ver e dizer um espaço, e de classificar e nomear as práticas e os procedimentos de uma população. E, ao mesmo tempo em que se legitima, enfrenta resistências e divergências, como expressão das práticas cotidianas que, oscilando entre o novo e o antigo, busca se consolidar e se institucionalizar como verdade e, dessa forma, homogeneizar práticas, instituir identidades e silenciar as vozes destoantes.

A proposta da convivência, embora sendo uma ideia elaborada a partir de uma intencionalidade discursiva que apresenta, em diversas abordagens, as possibilidades de se conviver com esse ambiente sem agredi-lo, não se institui ou se legitima como uma questão unânime e homogênea, revelando fissuras e brechas. Essas concepções revelam que o conviver não se resume apenas às pessoas que habitam esse espaço, mas abrange todo um contexto político, cultural, social e econômico.

Em suma, a mudança que vem ocorrendo no semiárido brasileiro, com o deslocamento do discurso do combate à seca para a concepção da convivência, vem também instituindo um redimensionamento de concepções, enunciados e dizeres sobre o que é o Semiárido. A ideia da convivência, como contraponto ao descaso histórico para com o Semiárido brasileiro, baseia-se, por exemplo, em evidências que caracterizam a região como espaço de problematizações pertinentes ao ecossistema da Caatinga, sua diversidade e as possibilidades de desenvolvimento sustentável na região. Essas mudanças, se assentadas em enunciados como o da convivência, possibilitam a (re)elaboração de novas perspectivas de identificação e caracterização do sertão.

Portanto, a proposta da convivência com o Semiárido não é algo que sempre existiu, mas uma ideia que surgiu graças à atuação de entidades governamentais e não governamentais, e vem ganhando cada vez mais espaço e legitimidade. A institucionalização desse discurso se operacionaliza a partir de um complexo encadeamento de redes e práticas sociais desenvolvidas, sobretudo, por organizações não governamentais (ONGs) e entidades religiosas, que ensaiam novas relações sociais, inventam novas interpretações desse espaço e dimensionam novas maneiras de ver e dizer o Semiárido. Trata-se de uma proposta que, ancorada na educação e no protagonismo social e político, pensa o sertanejo como parte integrante do seu meio, e que nele vive com dignidade e autonomia, sem repetir as experiências humilhantes da mendicância ou da retirância, sobretudo nos períodos de grandes estiagens. 
Neste contexto, a estratégia da convivência com o Semiárido compreende priorizar o modo vida nas condições socioambientais da região, considerando os seus limites e potencialidades, pressupondo novas formas de aprender a lidar com esse ambiente, valorizando a região semiárida.

Os projetos de convivência com o Semiárido, ao propor uma relação de interação e parceria entre o homem e o ambiente, têm como objetivo principal a superação das relações políticas, sociais e culturais que tradicionalmente construíram uma imagem deste território como inviável e improdutivo. Com efeito, o discurso da convivência considera fundamental a invenção de sujeitos ativos, autônomos e inventivos.

As ações desenvolvidas pelas entidades mostram como a ideia da convivência com o Semiárido se complexifica quando sai do campo do discurso articulado e elaborado, e ganha o território das práticas cotidianas. A visibilidade e dizibilidade revelados pelas falas dos agricultores demonstram que há ideias e práticas destoantes da realidade enfatizada pelas lideranças das entidades. Essas falas expressam a insatisfação e o descontentamento quanto ao tratamento dispensado às pessoas, às propostas e à própria perspectiva de convivência com o semiárido. Não se trata de desmerecer a atuação dos líderes, mas de voltar as atenções também para os resistentes, de modo a promover o diálogo para uma melhor convivência dentro das comunidades.

Em suma, a ideia de convivência com o Semiárido, mesmo ganhando espaço no debate intelectual e no diálogo social, não se expressa, na prática, como uma ideia totalizante e unificadora. Ela sofre as tensões e contradições na sua operacionalização. No entanto, é fundamental perceber que esse diálogo que vem ocorrendo em inúmeras ONGs é responsável pela produção de uma compreensão político-pedagógica que busca ressaltar a convivência com o semiárido como essencial para se pensar as diferentes possibilidades de reprodução dos modos de vida ali existentes.

\section{REFERÊNCIAS}

ALMEIDA, A. Paraíba e seus problemas. 3. ed. João Pessoa/PB: Secretaria de Educação e Cultura, 1980.

ALVIM, D. M. O rio e a rocha: resistência em Gilles Deleuze e Michel Foucault. Intuito, Porto Alegre, v. 2, n. 3, p. 78-90, nov. 2009. 
Pensamento indomado: história, poder e resistência em Michel Foucault e Gilles Deleuze. Dimensões, v. 24, p. 193-207, 2010.

BRANCO, G. C. As resistências ao poder em Michel Foucault. Trans/Form/ Ação, Marília, v. 24, n.1, 2001.

CHACON, S. S. O que é desenvolvimento sustentável? Definição da sustentabilidade para comunidades rurais carentes através do planejamento participativo. In: ENCONTRO NACIONAL DE ECONOMIA POLÍTICA. Fortaleza, 2000. Sociedade Brasileira de Economia Política.

FOUCAULT, M. A ordem do discurso. São Paulo: Loyola, 1999.

Dits et écrits. Paris: Gallimard, 1994. 4v.

GEWEHR, M. F. Desenvolvimento Sustentável e Agenda 21 Brasileira: implicações conceituais e especificas. Revista Jus Vigilantibus, 2006.

LIRA, M. T. dos R.; MOREIRA NETO, M. Discursos sobre convivência com o semiárido: invenções e dispersões. Relatório Parcial. Campina Grande: UFCG;/ PIBIC/CNPq, 2011/2011.

LIRA, M. T. dos R.; MOREIRA NETO, M. Discursos sobre convivência com o semiárido: invenções e dispersões. Relatório Parcial. Campina Grande: UFCG;/ PIBIC/CNPq, 2012/2013.

MALVEZZI, R. Semi-árido: uma visão holística. Brasília: Confea, 2007.

OLIVEIRA SILVA, M. R.; MOREIRA NETO, M. Relatório Parcial da Pesquisa UFCG/PIBIC/CNPq. Discursos sobre convivência com o semiárido: invenções e dispersões. Relatório Parcial. Campina Grande, UFCG/PIBIC/ CNPq. Campina Grande: UFCG;/PIBIC/CNPq, 2010/2011.

POLETTO, I. Da indústria da seca para a convivência como o Semiárido Brasileiro. In: Água de chuva: o segredo da convivência com o Semiárido brasileiro. São Paulo: Paulinas, 2001. Pp. 9-25.

SAMPAIO, S. S. Resistências. Revista Aulas. Dossiê Foucault, n. 3, dez. 2006; mar. 2007.

SHISTEK, H. Como conviver com o Semiárido. In: Água de chuva: o segredo da convivência com o Semiárido brasileiro. São Paulo: Paulinas, 2001. p. 41-61. 